ORIGINAL ARTICLE

\title{
Role of Presepsin in Predicting The Severity and Outcome of Community Acquired Pneumonia in Pediatrics.
}

\author{
Mohmed Sanad Nagiub', Mohamed Ahmed Arafa', Atef Goda Hussein", Mohamed Zaki \\ Abdallah $^{\mathrm{I} *}$.

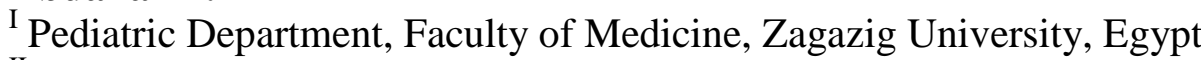 \\ II Biochemistry Department, Faculty of Medicine, Zagazig University, Egypt
}

\section{Corresponding author:}

Mohamed zaki abdallah abdelmoaty

Pediatric ICU, Zagazig General

Hospital, Pediatric Deparment,

Faculity of Medicine, Zagazig

University, Egypt

Mzakimzaki231@gmail.com

$\begin{array}{ll}\text { Submit Date } & 2019-03-26 \\ \text { Revise Date } & 2019-07-10 \\ \text { Accept Date } & 2019-07-12\end{array}$

\section{ABSTRACT}

Background: The aim of this study was to investigate the role of presepsin in evaluation of severity and outcome of community -acquired pneumonia in pediatric department of Zagazig University hospitals. Method: A prospective case control study was carried out at the pediatric Department of Zagazig University Children Hospitals during the period from February 2017 to October 2017. Results: In this study, there was statistically significant difference between case and control groups in Preserpin level. Also, there was statistically significant difference in presepsin level between cases that need ICU admission and mechanical ventilation and cases treated in ward only without need for ICU admission or M.V. There was statistically significant difference in presepsin level between survivors and non-survivors. Furthermore, There was statistically significant difference in presepin level and disease severity.in which presepsin is higher in severe than moderate and mild cases. A statistically significant positive correlation between Preserpin level and granulocytes, CRP, and significant negative correlation with platelets were reported. Acutoff point of presepsin $0.8(\mathrm{ng} / \mathrm{ml})$ was detected for diagnosis of the community acquired pneumonia calculated from ROC curves, and the area under the curve of presepsin was 0.833 with sensitivity $97.8 \%$ and specificity $72 \%$. Conclusion: It was concluded that Presepsin is a useful diagnostic and prognostic marker for pneumonia in Pediatrics. The present study suggests that Presepsin is a promising biomarker for reflecting the severity of Community- Acquired Pneumonia. Presepsin in combination with PRESS score may improve the predictive accuracy for severity and outcome of community acquired pneumonia in pediatrics.

Key words: Soluble CD 14, Presepsin; Community Acquired Pneumonia (CAP); Mechanical Ventilation (MV).

\section{INTRODUCTION}

\begin{abstract}
Community-acquired pneumonia remains a common and serious illness despite the availability of new and potent antibiotics and effective vaccines. It is, moreover, one of the main causes of death in young children, especially in developing countries, accounting for approximately 2 million deaths, and $20 \%$ of
\end{abstract}

all deaths in children. The understanding of community-acquired pneumonia is rapidly expanding and the ability to prevent and treat the disease has improved in recent years. [1]

Accurate, objective, and early disease severity assessment and prediction of outcome in patients with community-acquired pneumonia are crucial for optimized 
management decisions regarding care setting, extent of assessment, and level of treatment.

CD14 is one of the leukocyte differentiation antigens, and is present in macrophages, monocytes, and granulocytes and their cell membranes. CD14 exists in two forms, membrane CD14 and soluble CD14 [2].

Soluble CD14-subtye; Presepsin; is produced by circulating plasma proteases activating cleavage of presepsin which is a new biomarker of sepsis [3].

Previous clinical studies have confirmed that Presepsin levels increased in sepsis and with severity of disease [4-6]. However, the correlation between presepsin and communityacquired pneumonia has not yet been determined. So, the aim of this study was to investigate whether presepsin has adiagnostic and prognostic role in patients with community -acquired pneumonia and correlate these levels with severity and outcome of community acquired pneumonia in pediatrics.

\section{METHODS}

A prospective case control study was carried out at the Pediatric Department at Zagazig University Children Hospitals during the period from February 2017 to October 2017.Ninty infant and children patients participated in the study 45 were with community acquired pneumonia admitted to Pediatric Department Of Zagazig University as case group and similar number of control comparable with case group.

Inclusion criteria were patients diagnosed as community acquired pneumonia between the age of 2 months and 10 years. Exclusion criteria were as follows: Age less than 1 month, terminal stages of disease (malignancy, end-stage liver or renal diseases), hospitalized cases within 14 days before onset of symptoms, cystic fibrosis, active pulmonary tuberculosis, severe immune compromised, coagulopathy, systemic anticoagulant treatment, pretreatment outside hospital, and patient or relatives who refuse to participate in the study.

All patients were subjected to the following: full history taking including cough, Fever, difficult breathing and flu like symptoms, past history of previous pneumonia, vaccination history, dietetic history in infants and family history of similar illness.

Full clinical examination including General examination, vital signs and systemic examination with especial emphasis on cardiac (gallop rhythm, tachycardia, murmurs) and abdominal examination (distention, tenderness, organomegaly), local chest examination by Inspection for (retractions, chest movements, localized bulge or localized retraction and signs of respiratory distress), palpation for (tracheal shift, palpable bronchi), percussion and auscultation for (breath sounds and adventious sounds). Severity of pneumonia was classified according to PRESS score [7].

All patients were subjected to Complete blood count (CBC),C reactive protein (CRP),Chest $\mathrm{X}$ ray, abdominal ultrasound, CT (if needed) and Serum presepsin level was measured using ELISA (Sandwich technique).

Written informed consent was obtained from all participants; parents and the study was approved by the research ethical committee of Faculty of Medicine, Zagazig University. The work has been carried out in accordance with The Code of Ethics of the World Medical Association (Declaration of Helsinki) for studies involving humans.

\section{Statistical analysis}

Data entry and statistical analyses were performed using SPSS (statistical package of social sciences) version 21 Categorical data were expressed in number and percentage. Continuous normally distributed data were expressed in mean and standard deviation. Continuousn on normally distributed data were expressed in median and range. The quantitative data were examined by Kolmogrov Smirnov test for normality of data.

\section{RESULTS}

In this study, there was no statistical significant difference between case and control groups regarding age and sex. (Table 1).Cases were classified according to the severity by the PRESS score into (40\%) mild, $(20 \%)$ moderate and $(40 \%)$ severe. (Table 2). In this study 45 cases were included, 10 cases of them need 
ICU admission and mechanical ventilation. Survivors were 41 cases and 4 cases died. (Table 3)

In this study, there was statistically significant difference between case and control groups in Preserpin level (Table 6). Also there was statistically significant difference in presepsin level between cases that need ICU dmission and M.V. and cases treated in ward only without need for ICU admission and M.V (Table 8). There was statistically significant difference in presepsin level between survivors and non-survivors (Table 9). In addition, there was statistically significant difference in presepin level with disease severity in which presepsin is higher in sever than moderate and mild cases (Table 10). Furthermore, there was statistically significant positive correlation between Presepsin level and total PRESS score (Table 11).

Table 1. Socio-demographic characteristics of the studied groups:

\begin{tabular}{|c|c|c|c|c|c|c|}
\hline \multirow[t]{2}{*}{ Variable } & \multicolumn{2}{|c|}{ Case (45) } & \multicolumn{2}{|c|}{ Control (45) } & \multirow[t]{2}{*}{ t-test } & \multirow[t]{2}{*}{ p-value } \\
\hline & \multicolumn{2}{|c|}{$\begin{array}{c}\text { mean } \pm \text { SD } \\
\text { median } \\
(\text { Range) }\end{array}$} & \multicolumn{2}{|c|}{$\begin{array}{c}\text { mean } \pm \text { SD } \\
\text { median } \\
(\text { Range) }\end{array}$} & & \\
\hline Age (months) & \multicolumn{2}{|c|}{$\begin{array}{c}17.6 \pm 6.17 \\
(1.5-120)\end{array}$} & \multicolumn{2}{|c|}{$\begin{array}{c}23.1 \pm 7.18 \\
(1.5-10.8)\end{array}$} & 0.9 & 0.3 \\
\hline Variable & F (45) & $\%$ & F (45) & $\%$ & & p-value \\
\hline $\begin{array}{l}\text { Sex : } \\
\text { Male } \\
\text { Female }\end{array}$ & $\begin{array}{l}19 \\
26\end{array}$ & $\begin{array}{l}42.2 \\
57.8\end{array}$ & $\begin{array}{l}23 \\
22\end{array}$ & $\begin{array}{l}51.1 \\
48.9\end{array}$ & 0.7 & 0.4 \\
\hline
\end{tabular}

Table 2. Severity scoring in the case group according to PRESS SCORE:

\begin{tabular}{|c|c|c|}
\hline Severity scoring & \multicolumn{2}{|c|}{ Case group (45) } \\
\cline { 2 - 3 } & F (45) & \% \\
\hline Mild & $\mathbf{1 8}$ & $\mathbf{4 0}$ \\
\hline Moderate & $\mathbf{9}$ & $\mathbf{2 0}$ \\
\hline Severe & $\mathbf{1 8}$ & $\mathbf{4 0}$ \\
\hline
\end{tabular}


Table 3. ICU admission and need for Mechanichal ventilation of the case group:

\begin{tabular}{|c|c|c|}
\hline $\begin{array}{c}\text { Icu admission and need for } \\
\text { Mechanical ventilation }\end{array}$ & The case group & $\%$ \\
\hline Yes & NO (45) & $\mathbf{2 2 . 3}$ \\
No & $\mathbf{1 0}$ & $\mathbf{7 7 . 7}$ \\
\hline Survival & 35 & $\%$ \\
\hline Survivors & The case group & $\mathbf{9 1 . 2}$ \\
\hline Non-survivors & NO (45) & $\mathbf{8 . 8}$ \\
\hline
\end{tabular}

ICU: intensive care unit.

Table 4. Comparing laboratory parameters between case and control groups:

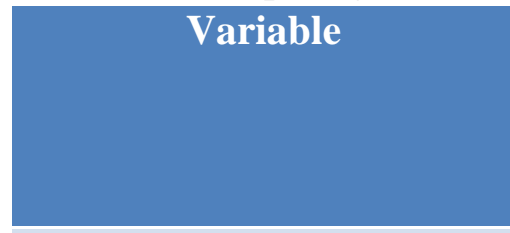

HB (g/dl)

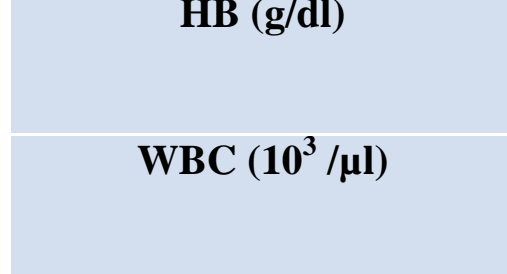

Neutrophil
$\left(10^{3} / \mu \mathrm{l}\right)$

\section{Lymphocytes $\left(\mathbf{1 0}^{3} / \mu \mathrm{l}\right)$}

Case (45)
mean \pm SD
median
(Range)

$10.1 \pm 1.3$ 9.9 $(7.8-13.4)$ $10.9 \pm 3.1$ 11.4 $(5.2-22)$

\section{$5.6 \pm 1.7$} 6.2 (0.9-14) $4.4 \pm 1.6$ 4.5 (0.7-9.1)

\section{Platelet $\left(1^{3} / \mu \mathrm{l}\right)$}

Platelet $(10 / \mu \mathrm{l})$

\section{$315.7 \pm 102.8$} 304 (106-498)

BUN (mg/ dl)

$9.24 \pm 3.06$

Creatinin(mg/ dl) SGOT (u/L)

\section{SGPT (u/L)}

\begin{tabular}{|l|l|}
\hline \\
\hline \\
$x$
\end{tabular}

Control $(45)$
mean \pm SD
median
(Range)

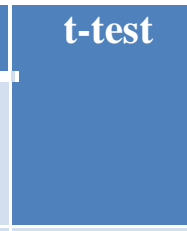

p-value

$10.7+1.3$ 8 (1.5-10.8)

$7.2 \pm 2.2$

2.6

0.01*

7

$$
\text { (4-12) }
$$

$3.2 \pm 1.1$

3

(1.9-5.5)

$3.7 \pm 1.5$

3.5

(1.8-7.9)

$333 \pm 101$

330.5

(139-787)

$9.29 \pm 2.95$

6.3

$0.001 * *$

5.6

$0.001 * *$

2.3

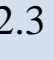

3

0.02*

3.4

0.003*

$9.29 \pm 2.95$

1.21

0.932

$0.77 \pm 0.21$

0.551

0.056

$31.39 \pm 5.64$

1.64

0.729

$27.40 \pm 7.76$

1.79

0.401

* Statistically significant difference $(\mathrm{P} \leq 0.05)$

** Statistically highly significant difference $(\mathrm{P} \leq 0.001)$

Hb: hemoglobin, WBCs: white blood cells, BUN: blood urea nitrogen 
Table 5. Comparison of presepsin level (ng/ml) between male and female in case and control group:

\begin{tabular}{|c|c|c|c|c|}
\hline Variable & $\begin{array}{c}\text { Male } \\
\text { mean } \pm \text { SD }\end{array}$ & $\begin{array}{c}\text { Female } \\
\text { mean } \pm \text { SD }\end{array}$ & t-test & p-value \\
\hline Control group & $1.39 \pm 2.3$ & $1.31 \pm 2.1$ & 0.06 & 0.95 \\
\hline Case group & $6.2 \pm 3.55$ & $5.91 \pm 4.5$ & 0.98 & 0.33 \\
\hline Total group & $\mathbf{3 . 2 5} \pm 1.2$ & $3.19 \pm 1.9$ & 0.4 & 0.68 \\
\hline
\end{tabular}

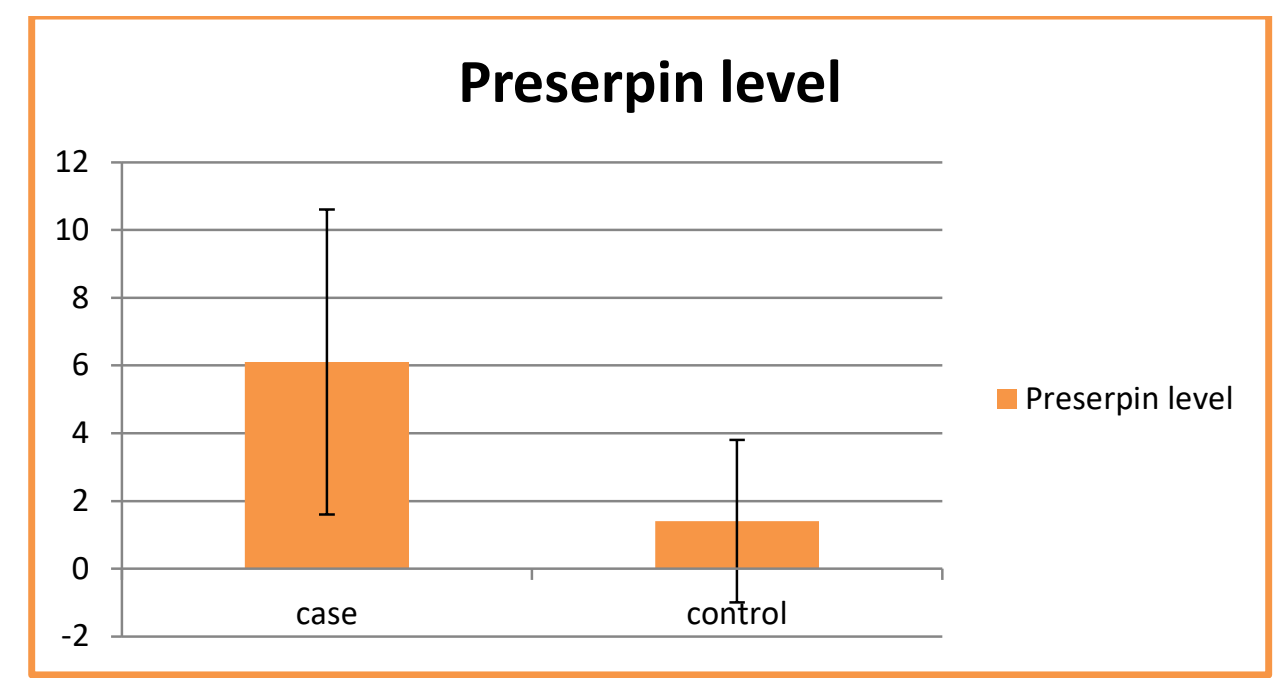

Fig 1. Bar chart for comparing Preserpin level between case and control groups:

ROC Curve

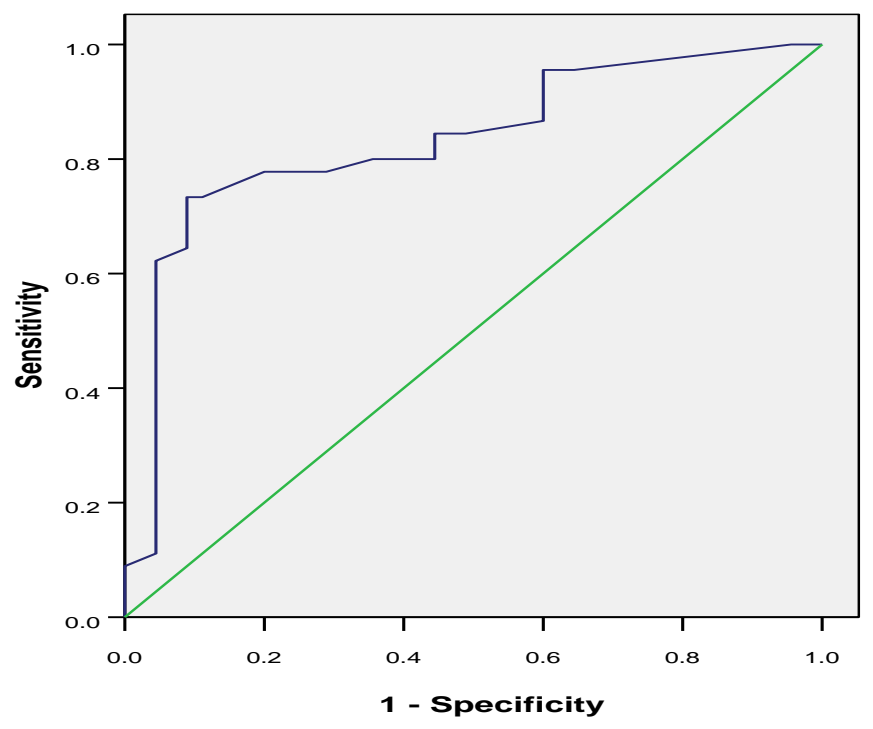

Diagonal segments are produced by ties.

Figure 2. ROC curve of presepsin as a predictor for community-acquired pneumonia. 


\section{DISCUSSION}

Previous clinical studies have confirmed that Presepsin levels increased in sepsis and with severity of disease [4-6].However, the correlation between Presepsin and communityacquired pneumonia has not yet been determined.

In this study, there was statistically significant difference between case and control groups in hemoglobin level, total leucocytic count, granulocytes, lymphocytes and CRP level. These data came in agreement with several studies done among Egyptian children about anemia as a risk factor for acute lower respiratory tract infections as. El sakka et al [8] reported that low hemoglobin level was found to be a risk factor for acute lower respiratory tract infections as it was detected in $56.25 \%$ of bronchiolitis cases, $62.5 \%$ of pneumonia cases and $42.71 \%$ of the control group. Also Harris et al [9] showed in a study done among Ecuadorian children, they studied anemia and air pollution as risk factors for acute lower respiratory tract infections. They found that anemic children are at increased risk of acute respiratory infection hospitalization compared to healthy non-anemic children.

They explained their findings by that the central pathophysiological deficit in acute lower respiratory tract infections is poor tissue oxygenation and anemia independently decreases oxygen delivery.

Researchers found that any inadequate supply of iron to body tissues is detrimental to immunity, the effects of iron deficiency anemia on immune function, and increase in susceptibility to infections are well established. [10]

On the other hand, a study performed by Broor et al [11] reported that anemia was not found to be a risk factor for acute lower respiratory tract infections in 512 infants and children below 5 years of age.

In this study, there was statistically significant difference between case and control groups regarding platelets count. The current report come in agreement with Martínez et al [12] who studied the Platelet count as a marker of outcome in community-acquired pneumonia. They found that Lower platelet counts were associated with an increase of severity of Pneumonia and more frequently complications in patients with community-acquired pneumonia.

Furthermore, this study revealed that there was statistically significant difference between case and control groups in Preserpin level.

In comparison with this study, Klouche et al [13] who investigated the diagnostic and prognostic value of soluble Presepsin for sepsis and community acquired pneumonia in ICU patients, they found that Plasma levels of Presepsin was significantly higher in septic than in non-septic patients and in septic shock as compared to others.

Also in agreement with this study Ulla et al [14] who evaluated the diagnostic and prognostic value of Presepsin in the management of sepsis in the emergency department, they found that elevated concentrations of presepsin at presentation were observed in septic patients compared to control patients.

In the current study that there was statistically significant difference in presepsin level between cases that need ICU admission and M.V. and cases treated in ward only without need for ICU admission and M.V.

In agreement with this study, Klouche et al [13], who found that Presepsin levels were also predictive of ICU mortality in sepsis and in severe community-acquired pneumonia patients.

Comparing presepsin level between the survivors and non-survivors groups there was statistically significant difference in presepsin level between survivors and non-survivors.

These findings were consistent with Ulla et al [14], who found that presepsin values were significantly higher in nonsurvivor septic patients than in survivors.

Also in agrrment with this study Liu et al [15], revealed that plasma Presepsin levels were significantly higher in nonsurvivors than in survivors. 
Matera et al [20] also found that: Presepsin levels were significantly higher in non-survivors versus survivors.

In this study, there was statistically significant difference in presepin level and disease severity, as presepsin was higher in severe than moderate and mild cases.

This come in agreement with Liu et al [15] who found that plasma presepsin levels were significantly higher in severe community acquired pneumonia patients than mild and moderate cases.

Despite there is much interest about presepsin, there are very few studies about presepsin in the pediatric population and so, there is lack of information about its reference range in this category of population [17].

The current cutoff point of presepsin $0.8(\mathrm{ng} / \mathrm{ml})$ was detected for diagnosis of the community acquired pneumonia calculated from ROC curves, and the area under the curve of presepsin was 0.833 with sensitivity $97.8 \%$ and specificity $72 \%$.

In comparison with this study Klouche et al [13], who found that The AUCs (areas under the curve) calculated from ROC curves were 0.75 for Presepsin, At a cutoff value of $466.5 \mathrm{pg} / \mathrm{mL}$, sensitivity and specificity of Presepsin to severe sepsis and septic shock diagnosis were 90 and $55 \%$, respectively.

While Ulla et al [14] found that the areas under the curve (AUCs) calculated from the ROC curve were 0.701 for presepsin, the best diagnostic cutoff for presepsin was 600 $\mathrm{pg} / \mathrm{ml}$. At that level, sensitivity and specificity were $78.95 \%$ and $61.90 \%$ respectively.

Also $\mathrm{Wu}$ et al [18].who evaluated Comparison of diagnostic accuracy in sepsis between presepsin, procalcitonin, and Creactive protein, found that eighteen studies, comprising 3470 patients, met the inclusion criteria. The pooled diagnosis sensitivity and specificity of presepsin for sepsis were 0.84 and 0.76 respectively and AUC was 0.88 .

On the other hand, Tong et al [16] who conduct study to examine Presepsin as a diagnostic marker for sepsis, they found that sensitivity and specificity of presepsin were
$0.83 \mathrm{ng} / \mathrm{ml}$ and $0.81 \mathrm{ng} / \mathrm{ml}$, respectively, with a relatively high rate of missed diagnosis $(17 \%)$ and misdiagnosis (19\%). AUC was 0.89, indicating good diagnostic performance.

A possible source of heterogeneity came from the use of different specimen types. Our subgroup analysis result suggested that the use of whole blood had higher specificity than plasma, with statistical significance. Wu et al [18].

In comparison with this study, Klouche et al [13] found that Plasma level of Presepsin were useful for the diagnosis of severe sepsis, septic shock and severe Community acquired pneumonia and may predict ICU mortality in these patients.

Also Ulla et al [14] found that presepsin was useful in the early diagnosis of infection in a complex population of patients with sepsis, severe sepsis and septic shock who presented to the emergency department .Presepsin showed a significant prognostic value, and initial values were significantly correlated with hospital mortality of patients affected by sepsis, severe sepsis or septic shock.

While $\mathrm{Wu}$ et al [18] founded that presepsin is a promising marker for diagnosis of sepsis as procalcitonin.

And Matera et al 2017 [20] also found that Presepsin revealed an optimal prognostic performance in patients with severe sepsis and provided interesting diagnostic value. Prediction of outcome in critically ill patients crucial to optimize management decisions and level of treatment.

In comparison with this study, Masson et al [19] found that presepsin measurements may be of clinical importance for early risk stratification and provide useful prognostic information in these patients.

Our study was one of the few works that were conducted on children with pneumonia, however; the small sample size lead to decreased statistical power. It was believed that this study might serve as a preliminary report that paves way for further investigations on a larger scale and with a longitudinal design for better assessment of the role of presepsin in 
diagnosis and prognosis of pneumonia in children.

\section{CONCLUSION}

Presepsin is a useful diagnostic and prognostic marker for pneumonia in Pediatrics the present study suggests that Presepsin is a promising biomarker for reflecting the severity of Community- Acquired Pneumonia. Presepsin in combination with PRESS score may improve the predictive accuracy for severity and outcome of community acquired pneumonia in pediatrics.

\section{Study Limitation}

Relatively small sample size due high cost concerning measurement of presepsin and procalciton. It was a single-center study (Zagazig University).

Serial measurement of the biomarkers studied could not be done to detect the level after time of diagnosis

\section{Declaration of interest}

The authors report no conflicts of interest. The authors alone are responsible for the content and writing of the paper.

Funding information None declared

\section{REFERENCES}

1- Sinaniotis CA, Sinaniotis AC. Communityacquired pneumonia in children. Current Opinion in Pulmonary Medicine. 2005;11(3):218-25.

2- Landmann R, Muller B, Zimmerli W. CD14, new aspects of ligand and signal diversity. Microbes Infect. 2000;2(3):295-304.

3- Mussap M, Noto A, Fravega M, Fanos V. Soluble CD14 subtype presepsin (sCD14-ST) and lipopolysaccharide binding protein (LBP) in neonatal sepsis: new clinical and analytical perspectives for two old biomarkers. The Journal of Maternal-Fet al \& Neonatal Medicine. 2011;24(sup2):12-4.

4- Yaegashi Y, Shirakawa K, Sato N, Suzuki Y, Kojika M, Imai S, et al. Evaluation of a newly identified soluble CD14 subtype as a marker for sepsis. Journal of Infection and Chemotherapy. 2005;11(5):234-8.

5- Shozushima T, Takahashi G, Matsumoto N, Kojika M, Okamura Y, Endo S. Usefulness of presepsin (sCD14-ST) measurements as a marker for the diagnosis and severity of sepsis that satisfied diagnostic criteria of systemic inflammatory response syndrome. Journal of Infection and Chemotherapy. 2011;17(6):764-9.

6- Endo S, Suzuki Y, Takahashi G, Shozushima T, Ishikura H, Murai A, et al. Usefulness of presepsin in the diagnosis of sepsis in a multicenter prospective study. Journal of infection and chemotherapy. 2012;18(6):891-7.

7- Miyaji Y, Sugai K, Nozawa A, Kobayashi M, Niwa S, Tsukagoshi H, et al, Kimura H, Mori M. Pediatric respiratory severity score (PRESS) for respiratory tract infections in children. Austin Virol and Retrovirology. 2015;2(1):1009.

8- EI Sakka AS, Imam SS, Amer HA, Moustafa SA. Vitamin D deficiency and low hemoglobin level as risk factors for severity of acute lower respiratory tract infections in Egyptian children: A case-control study. Egyptian Pediatric Association Gazette. 2014;62(1):1-7.

9- Harris M, Clark J, Coote N, Fletcher P, Harnden A, McKean M, et al. British Thoracic Society guidelines for the management of community acquired pneumonia in children: update 2011. Thorax. 2011;66(Suppl 2):ii1-23.

10- Koskenkorva-Frank TS, Weiss G, Koppenol WH, Burckhardt S. The complex interplay of iron metabolism, reactive oxygen species, and reactive nitrogen species: insights into the potential of various iron therapies to induce oxidative and nitrosative stress. Free Radical Biology and Medicine. 2013;65:1174-94.

11- Broor S, Pandey RM, Ghosh M, Maitreyi RS, Lodha R, Singhal T, et al. Risk factors for severe acute lower respiratory tract infection in under-five children. Indian pediatrics. 2001;38(12):1361-9.

12- Martínez D, Sanz F, Fernández E, Cervera A, Briones ML, Aguar MC, et al. Platelet count is a marker of outcome in communityacquired pneumonia. European Respiratory Journal. 2013; 42: 4377.

13- Klouche K, Cristol JP, Devin J, Gilles V, Kuster N, Larcher R, et al. Diagnostic and prognostic value of soluble CD14 subtype (Presepsin) for sepsis and community-acquired pneumonia in ICU patients. Annals of intensive care. 2016;6(1):59.

14- Ulla M, Pizzolato E, Lucchiari M, Loiacono M, Soardo F, Forno D, et al. Diagnostic and prognostic value of presepsin in the management of sepsis in the emergency department: a multicenter prospective study. Critical Care. 2013;17(4):R168. 
15- Liu B, Yin Q, Chen YX, Zhao YZ, Li CS. Role of Presepsin (sCD14-ST) and the CURB65 scoring system in predicting severity and outcome of community-acquired pneumonia in an emergency department. Respiratory medicine. 2014;108(8):1204-13.

16- Tong X, Cao Y, Yu M, Han C. Presepsin as a diagnostic marker for sepsis: evidence from a bivariate meta-analysis. Therapeutics and clinical risk Management. 2015;11:1027.

17- Osman AS, Awadallah MG, Tabl HA, Abed NT, Goudah ES. Presepsin as a novel diagnostic marker in neonatal septicemia. The Egyptian Journal of Medical Microbiology. 2015;38(3174):1-6.

18- Wu CC, Lan HM, Han ST, Chaou CH, Yeh CF, Liu SH, Li CH, et al. Comparison of diagnostic accuracy in sepsis between presepsin, procalcitonin, and C-reactive protein: a systematic review and meta-analysis. Annals of intensive care. 2017;7(1):91.

19- Masson S, Caironi P, Spanuth E, Thomae R, Panigada M, Sangiorgi G,et al. Presepsin (soluble CD14 subtype) and procalcitonin levels for mortality prediction in sepsis: data from the Albumin Italian Outcome Sepsis trial. Critical care. 2014;18(1):R6.

20- Matera G, Quirino A, Peronace C, Settembre P, Marano V, Loria MT, et al. Soluble CD14 subtype - a new biomarker in predicting the outcome of critically ill septic patients. The American journal of the medical sciences. 2017;353(6):543-51.

To Cite This Article: Nagiub MS, Arafa MA, Hussein AG, Abdallah MZ*.. Role of Presepsin in Predicting The Severity and Outcome of Community Acquired Pneumonia in Pediatrics.. Zumj May. 2020(26) No.3,375383; doi: 10.21608/zumj.2019.10906.1138 